\title{
Promover o ensino da matemática num contexto de formação profissional com STEM
}

\section{Promote mathematics teaching throught a teachers' professional development context with STEM}

\author{
Maria Cristina Costa ${ }^{1}$ \\ António Domingos ${ }^{2,3}$
}

\begin{abstract}
Resumo. Este artigo descreve uma forma de promover o ensino da matemática, através de um contexto formativo que envolve atividades experimentais hands-on de STEM, recorrendo ao questionamento investigativo. Com uma abordagem qualitativa de natureza interpretativa, daremos conta deste contexto formativo, dando destaque à forma como a matemática foi trabalhada, a partir do tópico do som. Serāo apresentados, com mais pormenor alguns estudos de caso envolvendo professores que implementaram este tema, de forma interdisciplinar. Conclui-se que é possível trabalhar a matemática, a partir de STEM, ao nível do ensino básico, através de um contexto de desenvolvimento profissional colaborativo, onde os professores sāo apoiados na implementaçāo das suas práticas.
\end{abstract}

Palavras chave: Desenvolvimento profissional, hands-on, STEM, interdisciplinaridade, questionamento investigativo.

Fecha de recepción: 23 de noviembre de 2018. Fecha de aceptación: 23 de octubre de 2018.

1 UIED, UDMF, ESTT do Instituto Politécnico de Tomar, Portugal, ccosta@ipt.pt

2 UIED, DCSA, FCT da Universidade NOVA de Lisboa, Portugal, amdd@fct.unl.pt

${ }^{3}$ This work is supported by national funds through FCT - Foundation for Science and Technology, I. P., in the context of the project PTDC/CED-EDG/32422/2017 


\begin{abstract}
This paper describes a way to promote the teaching of mathematics, through a professional development context that involves STEM hands-on experiments applied resorting to the inquiry approach. With a qualitative methodology and an interpretative approach, we investigate how teachers developed mathematical tasks, from the sound topic, according to school syllabus. We also present some case studies, involving teachers who implemented this theme in an interdisciplinary way. It is concluded that it is possible to work mathematics based on STEM experiments, at primary schools, through a collaborative teachers' professional development context, that supports the teachers when they implement their practices.
\end{abstract}

Keywords: Professional Development, hands-on, STEM, interdisciplinarity, inquiry.

\title{
1. INTRODUÇÃO
}

Este artigo descreve uma forma de promover o ensino da matemática, ao nível do 1. Ciclo do Ensino Básico (1. CEB), através de um contexto formativo que envolve atividades experimentais hands-on de STEM (Science, Technology, Engineering and Mathematics) implementadas recorrendo ao questionamento investigativo. A principal questão que queremos investigar é: Em que medida os professores que participaram num contexto formativo com STEM criam e implementam tarefas relacionadas com o som, nomeadamente tarefas que envolvem a matemática? Quais as características deste contexto formativo que motivam os professores para se envolverem neste tipo de práticas?

A formaçāo de professores envolve workshops onde são introduzidos tópicos relacionados com STEM, tais como astronomia, matemática, eletricidade, som, robótica e tecnologia, entre outros. Os formadores, responsáveis pela condução dos workshops, são professores do ensino superior (universitário e politécnico) e investigadores nas áreas das ciências da educação, matemática, física, engenharia informática, engenharia eletrotécnica e de computadores, e tecnologias da informação e comunicação.

Em Portugal, o 1.ำ Ciclo do Ensino Básico (1. CEB) é constituído por quatro anos de escolaridade (dos 6 aos 10 anos), onde são ministradas as áreas curriculares de Matemática, Português e Estudo do Meio. Relativamente à Matemática 
uma das três finalidades assinaladas nas orientaçōes metodológicas, é a análise do mundo natural (Ministério da Educação, 2013):

A Matemática é indispensável a uma compreensāo adequada de grande parte dos fenómenos do mundo que nos rodeia (...) o domínio de certos instrumentos matemáticos revela-se essencial ao estudo de fenómenos que constituem objeto de atenção em outras disciplinas do currículo do Ensino Básico (M.E., 2013, p. 2).

A interdisciplinaridade e o questionamento investigativo estão patentes nos princípios orientadores da organizaçāo curricular e programas, das áreas curriculares de Estudo do Meio e de Matemática do 1. CEB. Nestes princípios orientadores é referido que "o Estudo do Meio está na intersecção de todas as outras áreas do programa, podendo ser motivo e motor para a aprendizagem nessas áreas." (ME, 2007, p. 101). Nos objetivos gerais do mesmo programa destaca-se que o aluno deve:

Utilizar alguns processos simples de conhecimento da realidade envolvente (observar, descrever, formular questōes e problemas, avançar possíveis respostas, ensaiar, verificar), assumindo uma atitude de permanente pesquisa e experimentaçāo. (ME, 2007, p. 103)

As indicaçōes metodológicas são que "A curiosidade infantil pelos fenómenos naturais deve ser estimulada e os alunos encorajados a levantar questōes e a procurar respostas para elas através de experiências e pesquisas simples" (ME, 2007, p. 115). Recomenda-se, ainda, que os alunos devem usar instrumentos de observação e medida, sendo importante que os mesmos façam registos daquilo que observam.

As Ciências são ministradas na área curricular de Estudo do Meio, a qual dispōe de cerca de três horas semanais (Ministério da Educação, 2007). Nesta área curricular, o som está enquadrado no domínio "Conhecimento do Meio Natural e Social" e subdomínio "Viver Melhor a Terra".

O estudo, aqui apresentado, faz parte de um projeto de intervenção pedagógica mais amplo, com início em 2013 (www.academiacap.ipt.pt), que envolve atividades laboratoriais de STEAMH (Science, Technology, Engineering, Arts, Mathematics and Heritage) promovidas por uma instituição do ensino superior em Portugal (Costa \& Domingos, 2018). No âmbito deste projeto, o som foi trabalhado com os participantes nas férias escolares e nas visitas às escolas 
(Ferreira, Neves, Costa e Teramo, 2017) passando de seguida a ser trabalhado com os professores, no contexto formativo acima descrito, de forma interdisciplinar procurando motivar os professores para também trabalharem a matemática.

O projeto mais amplo assenta numa metodologia baseada em Teacher Design Research (Bannan-Ritland, 2000), com o objetivo de promover o desenvolvimento profissional dos professores, correspondendo cada ano letivo a um ciclo de Design Research. Este artigo tem por base os dados recolhidos em dois anos letivos (2015/2016 e 2016/2017), procurando-se investigar que tarefas relacionadas com o som são criadas e implementadas pelos professores, nomeadamente tarefas que envolvem a matemática.

\section{REVISĀO DA LITERATURA}

Vários autores (Osborne \& Dillon, 2008; Rocard et al., 2007) identificam um declíneo no interesse dos jovens pelas STEM, o que irá comprometer o futuro das próximas geraçōes. Os mesmos autores salientam a necessidade de novas estratégias de ensino que despertem o interesse por estas áreas, realizando atividades experimentais centradas nos estudantes, relacionandoas com aspetos do seu dia a dia. Das várias estratégias recomendadas, destaca-se o inquiry (questionamento investigativo), como uma abordagem que dá mais espaço à observação, experimentação e construção, dando oportunidade à criança de construir o seu conhecimento, orientada pelo professor (PRIMAS, 2010; Rocard et al., 2007).

Realizar atividades experimentais hands-on usando o questionamento investigativo, conduz a melhorias significativas no desempenho dos alunos e desenvolve atitudes positivas relativamente à matemática e às ciências (Mody, 2015). Os professores reconhecem que esta abordagem capta a atençāo dos estudantes ao colocá-los a pensar "fora da caixa", tornando a sua aprendizagem significativa (Gillies \& Nichols, 2015).

Em Portugal, também são cada vez mais as recomendaçōes para um ensino interdisciplinar e centrado nos estudantes, onde se promove a resolução de problemas da vida real, estando patentes no programa para o ensino básico e, também, no projeto de autonomia e flexibilidade curricular dos ensinos básico e secundário (Diário da República, 2017). 
As ciências devem ser usadas para promover a interdisciplinaridade, por favorecerem a aprendizagem de outras áreas curriculares (Abell \& McDonald, 2006) e a sua integração no currículo prepara melhor os estudantes para a vida real (Beane, 1995). Relacionar a matemática com as ciências e tecnologia tem sido amplamente defendido por vários autores (Berlin \& Lee, 2005) mas não é fácil concretizar este objetivo (Baxter, Ruzicka, Beghetto, \& Livelybrooks, 2014). Treacy e O'Donoghue (2014) referem a existência de pouca investigação sobre a integração da matemática e ciências, bem como a falta de um modelo de ensino que englobe esta integração. Kim e Bolger (2016) defendem a criação de um currículo que integre as ciências e a matemática, devendo-se envolver os professores no desenvolvimento de liçōes interdisciplinares adequadas a esta abordagem. A integração de STEM deve ser feita nos primeiros anos de escolaridade, através do desenvolvimento profissional dos professores (Kermani \& Aldemir, 2015).

Os professores são a pedra basilar de qualquer processo de renovação pedagógica (Rocard et al., 2007). O sucesso de qualquer intervenção nas escolas não é possível sem o seu desenvolvimento profissional (Hewson, 2007). Além disso, ser parte de uma rede contribui para melhorar a qualidade do ensino (Rocard et al., 2007). É neste sentido que Geiger, Goos, Dole, Forgasz e Bennison, (2014) sugerem uma parceria entre investigadores e designers, que promova a integração de tarefas com abordagens pedagógicas adequadas, para melhorar o ensino e aprendizagem.

Ball (2003) refere que para melhorar a aprendizagem da matemática, é crucial dar oportunidades de aprendizagem aos professores, sendo fundamental o desenvolvimento cuidadoso de cursos, workshops e materiais bem desenhados e administrados. Os professores devem trabalhar e experimentar, os conteúdos e tarefas que se espera que venham a desenvolver em aula, num ambiente de reflexão onde se sintam apoiados (Afonso, Neves, \& Morais, 2005). As inovações devem ser apropriadas pelos professores que as implementam e transformadas na sua própria prática de modo a terem efeitos reais (Zehetmeier, Andreitz, Erlacher, \& Rauch, 2015). Num estudo preliminar Costa e Domingos (2017) concluem que é importante desenvolver o conhecimento dos professores sobre os tópicos de ciências e matemática, num ambiente colaborativo, onde se sentem apoiados, de modo a ganharem motivaçāo e confiança para inovarem as suas práticas.

Ferreira et al. (2017) integram o som com as tecnologias recorrendo a um paradigma socioconstrutivista e concluem que esta abordagem promove 0 
interesse das crianças e dos jovens pelas STEM. Neste estudo, recomendam implementar esta abordagem num contexto de formação profissional de professores promovendo a interdisciplinaridade.

Face ao exposto, os professores são a pedra basilar de qualquer processo de renovação pedagógica, sendo crucial promover o seu desenvolvimento profissional. Neste sentido, recomenda-se uma parceria entre investigadores e professores de forma a criar um contexto formativo colaborativo, onde os professores se sintam apoiados e tenham oportunidade de praticar o que se espera que venham a desenvolver em aula.

\section{METODOLOGIA}

Foi com base nos pressupostos e conclusões anteriores que foi criado o contexto formativo de professores que conduziu à investigação que aqui apresentamos. Neste sentido, foi realizado um trabalho colaborativo entre professores do ensino superior, centros de formação e agrupamentos de escolas para criar e desenvolver um programa de formação que responda às necessidades dos professores da regiāo.

É inquestionável a necessidade de atualizar os conhecimentos dos professores sobre as matérias que lecionam e sobre o conhecimento pedagógico para ensinar (Hewson, 2007). Este é um dos motivos porque a formaçāo contínua de professores é obrigatória em vários países, como é o caso de Portugal (OECD; 2014). No nosso país, compete ao Conselho Científico-Pedagógico da Formaçāo Contínua proceder à acreditação das açōes de formação contínua de professores e acompanhar o respetivo processo de avaliaçāo (http://www.ccpfc.uminho.pt/). As açōes de formação frequentadas pelos professores, participantes no estudo, foram acreditadas por este Conselho de Formação e consistem num total de 26 horas distribuídas por vários workshops ao longo de um ano letivo, com de 2 a 4 horas cada. Nestes workshops, os professores trabalham os conteúdos e manipulam os materiais, com o objetivo de conseguirem realizar as tarefas propostas com os respetivos alunos. Usando a pedagogia do questionamento investigativo, procura-se que os tópicos introduzidos sejam implementados de forma interdisciplinar, nomeadamente trabalhando a matemática. Após cada workshop, sobre cada um dos temas trabalhados, é solicitado aos professores que apresentem propostas de tarefas destinadas a implementar com os seus alunos, que integrem o tema abordado de forma interdisciplinar, nomeadamente com a 
matemática. No final de cada ciclo de Teacher Design Research (TDR), os professores apresentam uma reflexão crítica sobre o impacto da formaçāo recebida, descrevendo as práticas desenvolvidas com os seus alunos.

Uma particularidade deste programa de formação tem a ver com as visitas dos formadores à sala de aula dos professores, quer para realizar atividades experimentais hands-on, com os respetivos alunos (a fim de as exemplificar), quer para os ajudar, apoiar e observar nas tarefas por eles implementadas. Dos vários temas abordados na formaçāo daremos destaque às tarefas de matemática criadas a partir do tópico do som.

Nesta investigação iremos usar uma metodologia qualitativa de natureza interpretativa com recurso a estudos de caso (Cohen, Lawrence, \& Keith, 2007). Os dados sāo recolhidos, essencialmente, a partir de observaçōes participantes e de relatórios apresentados pelos professores. Para interpretar melhor alguns casos serão realizadas algumas entrevistas semiestruturadas. Um estudo de caso

é uma investigação empírica que se debruça sobre um fenómeno contemporâneo dentro do seu contexto de vida real podendo permitir uma generalização dos resultados obtidos (Yin, 2005). Recorremos, assim, ao estudo de caso de professores que participaram no contexto formativo, acima descrito, para descrever a forma como estes desenvolveram as tarefas relacionadas com o som com os respetivos alunos.

A primeira autora deste artigo é observadora participante, sendo responsável pela escrita dos diários e pela coordenação do projeto mais amplo. O segundo autor é responsável pela triangulação e validação de toda a informação envolvida. A observação participante decorre essencialmente nos workshops da formação presencial com os professores e nas visitas às respetivas aulas.

\subsection{PARTICIPANTES}

No ano letivo 2015/2016, participaram no programa de formação de 14 professores do sexo feminino de cinco escolas, com idades compreendidas entre os 42 e 58 anos e mais de 17 anos de serviço. No ano letivo 2016/2017 participaram 37 professores do sexo feminino e um do sexo masculino, de catorze escolas do 1. Primeiro Ciclo do Ensino Básico (1. CEB), com idades compreendidas entre os 35 e os 61 anos de idade e mais de 10 anos de experiência de ensino.

Neste artigo, os participantes são quatro professores do 1. CEB, envolvidos em pelo menos um dos anos letivos 2015/2016 e 2016/2017, correspondentes 
a dois ciclos de TDR. Começamos por destacar as perceções de uma professora que descrevem o contexto formativo. De seguida, fazemos estudos de caso de três professores que trabalharam o som. Um caso em que a professora não promoveu a interdisciplinaridade apesar de a sugerir e outro em que os professores criaram e implementaram tarefas de matemática relacionadas com o som. Para preservar a identidade dos participantes todos os nomes apresentados são fictícios.

\section{ANÁLISE E DISCUSSĀO DE DADOS}

Nesta seção introduzimos o contexto formativo que se devolveu durante dois anos letivos, descrevendo o tópico do som e a forma como este foi trabalhado, quer nas sessōes presenciais com os professores, quer nas visitas às escolas. De seguida, discutimos com mais pormenor as conceçōes de alguns dos professores que participaram neste contexto formativo passando de seguida aos estudos de caso.

\subsection{O TÓPICO DO SOM}

Nas açōes de formação, destinadas aos professores, o som é introduzido de forma teórico prática, sendo realizadas diversas atividades experimentais hands-on, relacionadas com este tema, recorrendo a diversos equipamentos. Alguns destes equipamentos são protótipos, desenvolvidos pelos formadores (professores na área da engenharia eletrotécnica e de computadores), sendo alguns deles no âmbito de projetos finais de curso, em colaboração com alunos finalistas, quer de licenciatura, quer de mestrado da instituição onde lecionam. Além disso, também são usados recursos computacionais, tais como softwares gratuitos que permitem medir a frequência e/ou intensidade do som, ou gerar/reproduzir áudio, bem como editar/visualizar a forma da onda e do espectro do som (Ferreira et al., 2017).

Nas sessōes com os professores são dadas várias ideias de implementação de atividades experimentais para usar em aula. Por exemplo, é sugerido que se façam medições do ruído através do sofware Sound Meter, ou que os alunos procurem ver nas suas casas o ruído produzido pelos seus eletrodomésticos, como a máquina de lavar roupa ou o frigorífico. Depois de fazerem os registos, devem partilhar os resultados com a turma para fazerem a discussão e 
tratamento dos dados resultantes. Nesta altura, os professores fazem sugestōes, como por exemplo gráficos de barras ou diagrama de caule e folhas. No entanto, nem sempre as concretizam, a não ser por insistência do formador, o que reforça a importância de haver apoio aos professores e acompanhamento, para estes inovarem as suas práticas.

Nas visitas dos formadores às aulas dos formandos para exemplificar as atividades, as sessōes decorrem recorrendo ao questionamento investigativo, inquirindo os alunos sobre os conceitos em estudo, valorizando as experiências e conhecimentos individuais dos mesmos, levando-os a realizar e visualizar experiências, de modo a que consigam tirar conclusōes. Para aferir sobre os conhecimentos dos alunos sobre o som, é realizado um questionário antes e depois da sessão destinada a este tema. Com este questionário, pretende-se por um lado identificar as perceçōes dos alunos sobre o som e, por outro, aferir se estas se alteraram após a sessão sobre o som. Até à escrita deste artigo o questionário já foi aplicado a mais de uma centena de alunos, distribuídos por várias turmas, dos 3. e 4. anos, do 1. CEB. A figura 1 apresenta um exemplo de respostas, de um aluno, à questão n.․ 2: "Faz um desenho sobre o que achas que é o som".

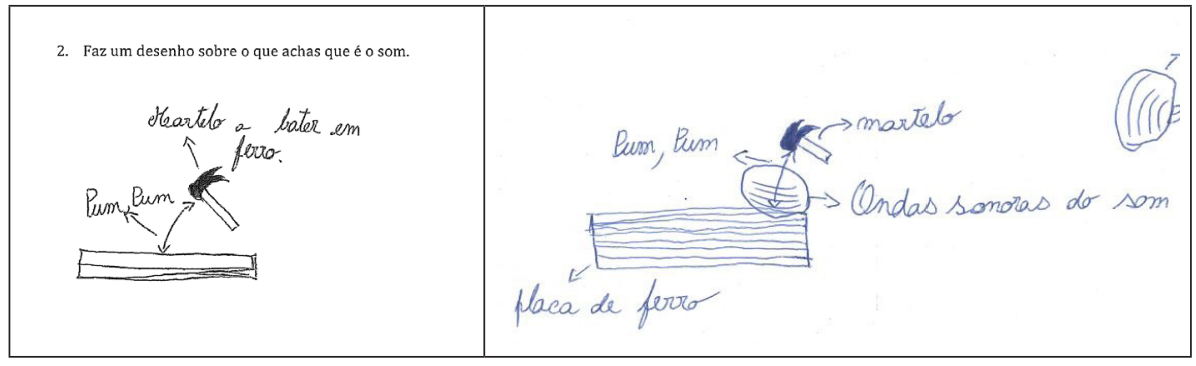

Figura 1. Resposta à questāo n.ำ 2, antes e depois da sessāo.

Nesta figura, é notório que o aluno associou o som ao ruído (assim como a maioria dos colegas) e aprendeu que o som é uma onda, tal como foi introduzido pelos formadores.

A figura 2 apresenta outro exemplo, neste caso, das respostas de um aluno à questão $n . .5$, relacionada com a velocidade do som. 


\section{O QUE VIAJA MAIS DEPRESSA? O SOM OU A LUZ?}

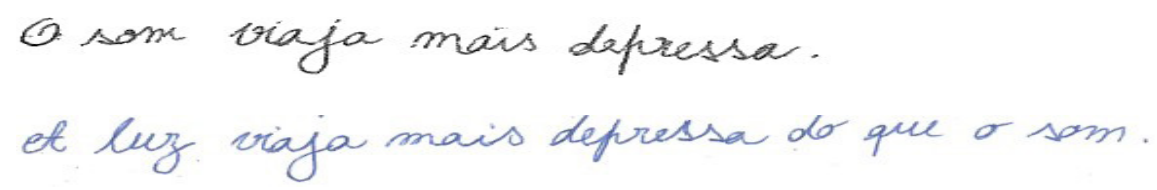

Figura 2. Resposta à questāo n. 5, antes e depois da sessāo.

Praticamente todos os alunos acham que o som é mais rápido do que a luz. Depois de questionados sobre "porquê?" esta ideia, muitos respondem "ouve-se logo o barulho".

Um exemplo usado para fazer a comparação entre o som e a luz é o fenómeno atmosférico da trovoada. Os formadores mostraram vídeos de trovoadas, onde claramente se via a luz (o relâmpago) e só mais tarde se ouvia o som. Os mesmos vídeos foram aproveitados para calcular a distância a que estava a trovoada, a partir do tempo que demorava a ouvir-se o trovão depois de observado o relâmpago.

No final, analisadas as respostas dos alunos aos questionários aplicados, verificou-se que todos os alunos responderam acertadamente a esta questão, assim como também interiorizaram que o som é uma onda que se propaga.

Estas experiências com os alunos são exemplificativas para os professores em formação, mas também são importantes para os formadores, porque o feedback dos alunos também os ajuda a preparar melhor a formação dos professores, no sentido de a adequar às necessidades dos mesmos, para uma maior eficácia da intervenção nas escolas.

\subsection{As PERCEÇŌES DA PROFESSORA AúREA RELATIVAMENTE AO CONTEXTO FORMATIVO}

Vamos começar por apresentar as perceçōes e reflexōes da professora Aúrea (61 anos), por entendermos que estas retratam o contexto formativo. O seguinte excerto de um relatório final (RF) desta professora mostra as espectativas iniciais que ela tinha sobre a formação que escolheu frequentar, bem como sobre a pertinência da mesma: 
Tornava-se fundamental frequentar uma formaçāo que concorresse para cabalmente configurar o modo de operacionalizar conteúdos, porventura envoltos nalguma opacidade, atenuasse ou resolvesse alguns hiatos nos meus conhecimentos teórico científicos e que transversalmente me proporcionasse uma reflexão coletiva sobre temas de Matemática, Ciências e Tecnologia através do encontro com outros professores e com especialistas teórico-práticos, para poder projetar um percurso de ensino/ aprendizagem da minha turma, com mais qualidade e potenciador do sucesso dos meus alunos (RF, junho de 2017).

A professora reconhece que a principal inovação desta formação tem a ver com a abordagem usada na mesma, enfatizando a grande componente experimental, tal como indica o seguinte excerto da sua reflexão final:

A etiqueta dada pelos formadores a esta oficina de formaçāo foi: Matemática, Ciências e Tecnologia: uma abordagem experimental no Ensino Básico. (...) Quanto a mim, é exatamente na açāo, na abordagem experimental que se centram a inovação e as novas asserçōes sobre o ensino/aprendizagem das ciências. Deixou de haver, segundo parece, um entendimento didático determinado e enformado por uma série de exercícios pré-estabelecidos e de resultados exatos. Há sim uma descentralizaçāo da açāo do professor do resultado para o processo e, nesta perspetiva, atrevo-me a dizer que muitos dos manuais existentes nāo correspondem a esta visāo de ensino, porque raramente enfatizam as tarefas propulsoras das verdadeiras caminhadas experimentais (RF, junho de 2017).

Logo na primeira reflexão, apresentada pela professora, após a primeira sessão presencial de formação, que decorreu em janeiro de 2017, ficaram patentes as metodologias e estratégias a implementar com os alunos em aula:

Ficaram subjacentes três ideias transversais: construir modelos mentais que façam sentido; incutir nos alunos o "empoderamento" isto é, levá-los a acreditarem que sāo capazes de construir a sua aprendizagem e finalmente projetar um ensino baseado em experiências, manipulaçōes e vivências (aliás como foi apanágio desta sessāo, onde tivemos vários momentos práticos demonstrativos) (...) Registo com muito apreço a abordagem clarividente do formador que promoveu o diálogo entre as metodologias de ensino e as ciências. (Relatório, janeiro de 2017) 
Mais uma vez, Aúrea destaca a forte componente experimental e as metodologias propostas nesta formação, como indica o seguinte excerto:

Todas as tarefas experimentais partiram de situaçōes problemáticas que serviram de ponto de partida e de ponto de chegada do processo de ensino/aprendizagem. $\mathrm{Na}$ verdade, o trabalho experimental promove nos alunos capacidades de exploraçāo, conjeturas e raciocínio lógico.

Esta formação permitiu não a repetição de ideias e fórmulas feitas, sejam elas da ordem do conteúdo, das metodologias ou dos materiais, mas sim um desenvolvimento de saberes consistentes, construídos a partir da reflexão sobre os materiais e as tarefas apresentadas pelos formadores. (RF, junho de 2017)

A professora Aúrea conclui dizendo que a formaçāo contribuiu para reforçar os seus conhecimentos e melhorar a sua atuação em aula:

Estou certa que reforcei os conhecimentos e a sensibilidade necessária para poder melhorar a minha atuaçāo na sala de aula, utilizando as variaçōes e modelaçōes que me foram (...) (RF, junho de 2017).

Quanto às propostas de tarefas da professora, para realizar em sala de aula, foram as relacionadas com a astronomia que mais promoveram a interdisciplinaridade com a matemática. No entanto, apesar de ter implementado tarefas relacionadas com a eletricidade e com o som, faltou explorar, com mais profundidade a parte da interdisciplinaridade, não apresentando, neste tópico, tarefas que envolvessem a matemática.

\subsection{AS PROPOSTAS DOS PROFESSORES RELACIONADAS COM O SOM}

Foram vários os professores que fizeram propostas de atividades relacionadas com o som tais como construção de um megafone, de um telefone de cordel, de um estetoscópio, xilofone colorido, exemplificação da propagação do som através de uma mola, produção do som por vibração, observar que o som faz vibrar areia ou açúcar, entre outros.

Muitos professores construíram com os seus alunos o protótipo que permite visualizar a voz, que Ihes foi apresentado na formaçāo, utilizando para tal um guiāo que thes foi anteriormente fornecido. Praticamente todos os professores 
que realizaram experiências hands-on reportaram o grande entusiasmo e empenho das crianças no decorrer das atividades. O entusiasmo e a participaçāo dos alunos com empenho, nestas visitas, acaba por ser um fator que motiva e "convence" os professores que vale a pena realizar este tipo de abordagem. Este aspeto também é referido quando os formadores dinamizam atividades experimentais com os alunos dos formandos. Nos relatórios finais, estes manifestam a importância destas intervençōes e insistem que estas devem continuar porque são muito enriquecedoras para os alunos e é sempre um momento especial e diferente no dia a dia dos mesmos. Este é um dos motivos que nos leva a concluir que sobre a importância destas demonstraçōes, em aula, para continuar a motivar os professores para estas abordagens.

Muitos relatórios dos professores, apresentam propostas de tarefas que incluem planos de aula e fichas de trabalho, criadas pelos próprios, para trabaIharam com os alunos. Foram vários os que dão conta de como o trabalho foi desenvolvido com os alunos, através de fotografias que ilustram a realização das atividades $e$, ainda, com o trabalho feito pelos alunos, nomeadamente as respostas destes às questōes das fichas, criadas pelos professores sobre os temas trabalhados.

De seguida, apresentaremos estudos de caso de professores que trabalharam o som quer recorrendo ao questionamento investigativo quer de forma interdisciplinar.

\subsection{O PERCURSO DA PROFESSORA MARIANA}

A professora Mariana (53 anos, 28 anos de serviço) participou no programa de formaçāo no ano letivo 2015/2016 (1. ciclo de TDR). Para além das sessōes presenciais com os restantes professores, a turma de Mariana (4. ano do $1 .$. CEB) recebeu os formadores para realizar experiências laboratoriais relacionadas com o som. Os formadores levaram equipamentos laboratoriais e usaram o questionamento investigativo para conduzir os alunos nas tarefas, levando-os a experimentar, discutir ideias e, por fim, tirar conclusōes. Durante este processo, a professora assumiu uma postura de observadora, atenta às atividades realizadas pelos formadores com os alunos. Apesar de ter frequentado o workshop sobre o som a professora deixou os formadores conduzirem as várias atividades experimentais.

Mariana referiu já ter frequentado várias formaçōes de ciências e que gostava de fazer algumas atividades relacionadas com as propostas no manual de 
Estudo do Meio, mas que nenhuma era igual às que os formadores estavam a implementar. A professora referiu, ainda, que esta formaçāo melhorou as metodologias habituais, nomeadamente a introdução do questionamento investigativo que reconhece ser eficaz para promover a aprendizagem dos alunos.

Numa outra sessāo, a Mariana propôs fichas de trabalho para aferir os conhecimentos dos alunos, sobre o que foi trabalhado em sala de aula, de acordo com o sugerido pelos formadores. O questionamento investigativo foi posto em prática nas várias questōes colocadas pela professora para despertar a curiosidade dos seus alunos e, também, para os conduzir no decorrer das tarefas, com vista à aprendizagem (figura 3).

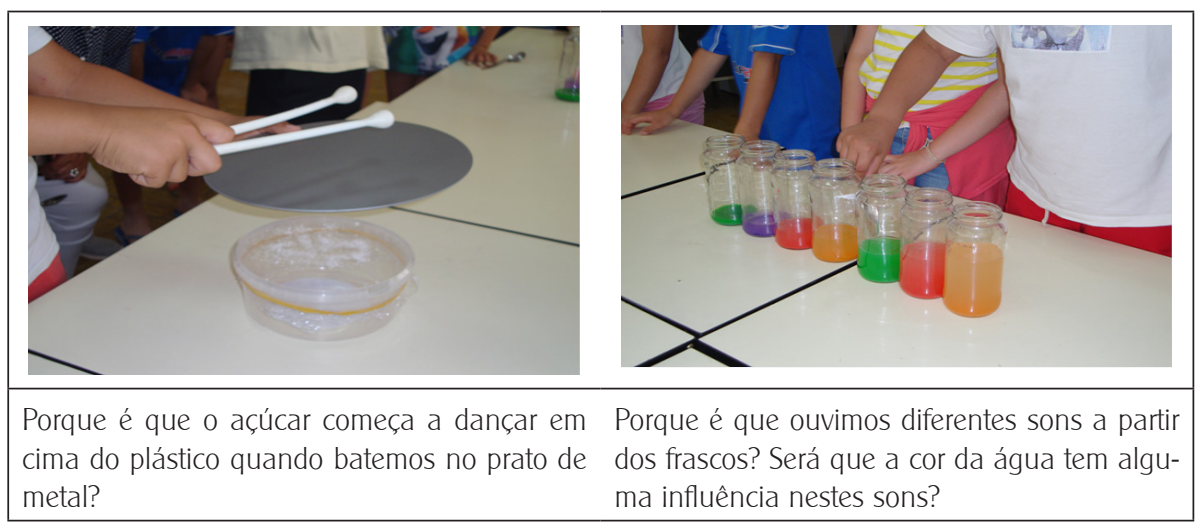

Figura 3. Exemplo do questionamento investigativo aplicado durante a realização da atividade experimental

No seu relatório final Mariana manifesta alguma insegurança, provocada pela falta de conhecimento de conteúdo pedagógico: “(...) falta de preparação dos professores para desenvolverem esta metodologia e a falta de conhecimentos/ fundamentação científica que promove a nossa insegurança". No entanto, reconhece a importância da formação recebida: "Adquirimos mais conhecimentos para melhorar as nossas práticas sobre o ensino das Ciências e da Matemática junto dos alunos." E continua dizendo: "Com estas atividades práticas os alunos puderam mexer e manusear coisas e objetos, pensar, refletir, planear, interpretar e discutir as situaçōes estudadas." O conhecimento pedagógico desta professora destaca-se quando refere: 
Privilegiámos o trabalho de grupo, tornando-os mais autónomos, mais sociáveis e responsáveis. Nāo descurámos todos os conhecimentos e conceçōes que os alunos possuíam e deveremos ter como ponto de partida esses conhecimentos para qualquer objeto de estudo (RF, junho 2016).

A interdisciplinaridade é referida pela professora quando fala em competências que poderão ser exploradas em disciplinas como o Português, Matemática, Cidadania e dando exemplos de como isso poderá ser feito:

Português, recolhendo informaçāo em textos sobre os assuntos em discussāo, descrevendo uma ou mais experiências que efetue, utilizando vocabulário científico, partilhando saberes...,

Matemática, construindo e interpretando gráficos, tabelas, cálculos, ... ( RF, junho 2016).

Em resumo, notou-se uma evolução na professora Mariana ao longo da formação recebida e na forma como ela recorre a esse conhecimento, para o desenvolvimento de tarefas em sala de aula. Apesar da professora propor várias tarefas relacionadas com as ciências, ela apresentou poucas evidências de aplicaçōes destes temas à matemática. No entanto, o questionamento investigativo foi aplicado no decorrer das tarefas (figura 3).

Tal como a professora Mariana, no primeiro ciclo de TDR, quase não houve evidências de tarefas interdisciplinares relacionadas com o som que envolvessem a matemática. Estes foi um dos aspetos que nos levou a reformular o segundo ciclo de TDR, de forma a insistir mais na importância de promover a interdisciplinaridade, nomeadamente criar tarefas de matemática a partir das atividades experimentais relacionadas com STEM. Neste sentido, foram dados mais exemplos desta abordagem bem como sugestōes de implementação em aula. Nas visitas às turmas dos formandos, também se insistiu nesta abordagem incentivando os formandos a implementarem as ideias que entretanto apresentavam aos formadores. Foi 0 caso dos professores que apresentamos de seguida.

\subsection{O PROFESSOR ANACLETO E A PROFESSORA MICAELA}

Os professores, Anacleto e Micaela, participaram na formação no ano letivo 2016/2017 (2.. ciclo de TDR) e escolheram trabalhar a matemática com os alunos, a partir do tópico do som. Micaela (48 anos, 27 anos de serviço) era titular 
de uma turma do 2.. ano do 1. CEB, com 16 alunos. Anacleto (48 anos, 27 anos de serviço) sem turma atribuída desenvolveu, em conjunto com a Micaela, as atividades para serem implementadas na turma de Micaela.

Os professores começaram por introduzir o tema com a seguinte questāo: " $\mathrm{O}$ que é o Som?". De seguida pediram aos alunos para desenharem o que achavam que era o som. Alguns destes desenhos mostram-se na figura 4.

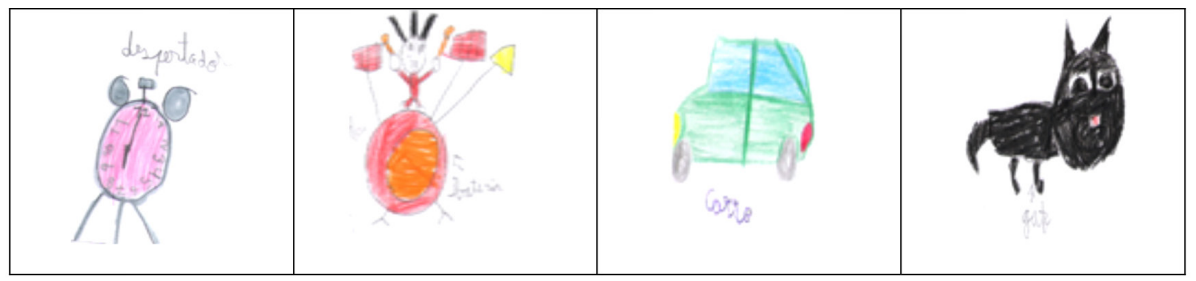

Figura 4. Perceçōes dos alunos relativamente ao som.

Depois de recolhidas as opiniōes dos alunos, os professores conduziram os mesmos na procura de respostas às questōes colocadas, recorrendo aos seus dicionários e à internet. Por exemplo, na Wikipédia aparece a seguinte definição: "É uma onda longitudinal que se propaga de forma circuncêntrica em meios materiais (sólidos, líquidos ou gasosos)". Apesar de esta não ser uma definição adequada a alunos deste nível de escolaridade, o objetivo dos professores foi o de desenvolver práticas investigativas com os seus alunos. Além disso, os professores mostraram algumas imagens e vídeos que ilustravam a propagaçāo do som como uma onda, de forma a dar significado à definição anterior.

Após mais alguma discussāo de ideias sobre o que é o som, colocaram-se mais questōes tais como: Para que serve o som? Como se produz? O que produz o som?

Novamente, ouvidas as opiniões dos alunos, passaram à discussão e investigação no sentido de obter respostas para as questōes colocadas. De seguida, foi construído um protótipo (cujo guiāo foi disponibilizado no workshop sobre o Som) que permite "visualizar" o som da voz. Após mais algumas experiências para introduzir este tema, passou-se à medição da frequência do som (em hertz) e da intensidade (em decibéis), recorrendo a equipamentos e softwares tais como o Sound Meter. Um exemplo da medição da intensidade do som, com um dos alunos da turma, encontra-se na figura 5. 


\begin{tabular}{|c|c|c|c|c|c|c|c|}
\hline $\begin{array}{c}\text { Açōes } \\
\text { Decibéis }\end{array}$ & Sussurrar & Falar & Rir & Chorar & Gritar & Cantar & $\begin{array}{c}\text { Bater } \\
\text { Palmas }\end{array}$ \\
\hline 30 & & & & & & & \\
\hline 40 & $X$ & & & & & & \\
\hline 50 & & & & & & & \\
\hline 60 & & $X$ & & & & & \\
\hline 70 & & & & & & & $X$ \\
\hline 80 & & & $X$ & $X$ & $X$ & $X$ & \\
\hline
\end{tabular}

Figura 5. Registo de mediçōes do som em decibéis.

A medição apresentada na figura 5 foi realizada com todos os alunos da turma e o resultado encontra-se na figura 6 .

\begin{tabular}{|l|c|c|c|c|c|c|c|}
\hline & 30 & 40 & 50 & 60 & 70 & 80 & 90 \\
\hline Sussurrar & & 12 & 4 & & & & \\
\hline Falar & & & & 4 & 9 & 3 & \\
\hline Rir & & & & & & 16 & \\
\hline Chorar & & & 3 & 13 & & & \\
\hline Gritar & & & & 3 & 8 & 5 & \\
\hline Cantar & & & & 4 & 8 & 4 & \\
\hline Bater palmas & & & & & 16 & & \\
\hline
\end{tabular}

Figura 6. Resultado das mediçōes do som em decibéis, dos alunos da turma.

Com os registos obtidos, a partir das mediçōes realizadas com cada um dos alunos, foram construídos gráficos (Figura 7). No primeiro, cada "cara" representa dois alunos que registaram aquela intensidade de som (em decibéis) enquanto falavam. No segundo, estão representadas as frequências de audição dos alunos (em hertz) no eixo horizontal e o número de alunos no eixo vertical, correspondendo cada retângulo colorido às frequências de audição de cada um dos alunos. 


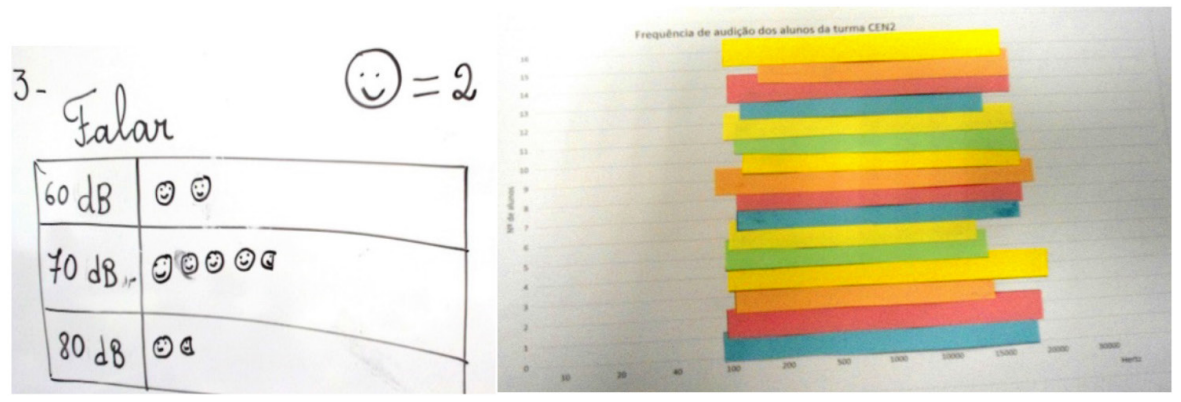

Figura 7. Organização e tratamento de dados.

Por fim, foram ainda realizados vários problemas, envolvendo cálculos a fim de trabalhar no contexto da matemática.

No relatório final, apresentado pela professora Micaela, esta reconhece que é possível trabalhar outros conteúdos a partir do som, fazendo uma abordagem transversal e destacando que:

As atividades práticas implementadas com os meus alunos, em conjunto com o professor Anacleto, permitiram verificar que é possível fazer uma abordagem transversal de conteúdos, relacionando a matemática, o estudo do meio, a expressão musical e dramática, e revelaram que os alunos se motivam e empenham com muito mais facilidade neste tipo de tarefas (RF, junho 2017).

Micaela também refere inovaçōes na aquisição de conhecimento de conteúdo pedagógico e das matérias a ensinar, reconhecendo que esta formação irá melhorar o seu desenvolvimento profissional:

Saliento que a ação de formação contribuiu para a aquisição de novos conhecimentos que me permitirāo melhorar o desempenho profissional e ter um impacto positivo na sala de aula, proporcionando aos alunos experiências diversificadas de aprendizagem e o desenvolvimento de competências científicas (Relatório final, junho 2017).

O professor Anacleto valoriza a forte componente prática da formação e o impacto que este tipo de abordagem teve nos seus alunos: 
Considero que esta formaçāo vem trazer à minha prática letiva, um leque mais alargado de possibilidades de novas atividades, a realizar no contexto da sala de aula. O mais interessante mesmo, é que estas novas abordagens, que tivemos na formaçāo, sāo na sua maioria, abordagens práticas, o que é muito bom. Com abordagens práticas os alunos ficam mais atentos e interessados, colaborando de forma mais ativa e empenhada, o que depois se nota na aprendizagem (RF, junho 2017).

Outro aspeto muito valorizado pelos professores é a visita dos formadores à sala de aula:

Um dos pontos mais altos, penso que é mesmo a visita dos formadores/professores, às turmas, pois, trata-se de um momento único na sala de aula. Os alunos vāo poder aprender/experimentar com a ajuda de técnicos credenciados e equipados com todo o material necessário (RF, Anacleto).

Os professores, Anacleto e Micaela, foram inovadores, no sentido em criaram tarefas relacionadas com o tópico do som que não estavam propostas nos manuais escolares, e promoveram a interdisciplinaridade, trabalhando a matemática e tecnologias, entre outros. Os professores também implementaram as tarefas recorrendo ao questionamento investigativo.

\section{CONSIDERAÇÕES FINAIS}

Os principais aspetos destacados pelos professores foram a forte componente prática, o ambiente colaborativo entre os pares e o apoio dos formadores, bem como a adequabilidade e pertinência dos tópicos abordados. As visitas às salas de aula, para além de serem muito apreciadas pelos professores, são úteis para os formadores pois esta experiência também os ajuda a preparar melhor a formação dos professores ao ficarem com a noção do impacto das atividades junto dos alunos. No entanto, nota-se que alguns professores continuam a preferir que sejam os formadores a conduzir as atividades, o que reforça a importância de continuar a promover o seu desenvolvimento profissional. Este aspeto tem vindo a ser assinalado por vários estudos internacionais (e.g., Murphy, Smith, Varley \& Razı, 2015) que também referem que este processo demora tempo. Com a experiência adquirida em dois ciclos de TDR reconhecemos a importância do acompanhamento e do apoio aos professores, bem como do 
tempo necessário para concretizar com eficácia um projeto de intervenção pedagógica. Este aspeto foi notório ao se verificar a proposta e implementação por parte dos professores de tarefas interdisciplinares mais ricas no 2.. ciclo de TDR. Atribuímos esta diferença ao reforço do apoio aos professores dando a oportunidade aos mesmos de treinarem as tarefas propostas, bem como ao reforço do acompanhamento em aula.

Todos os professores que realizaram atividades experimentais destacaram a importância do apoio dos formadores, bem como a pertinência de realizar este tipo de atividades. Também destacam o entusiasmo e a reação dos alunos por esta abordagem, referindo, ainda, que esta é uma forma de promover a aprendizagem significativa. Defendemos que esta constatação por parte dos professores é um dos fatores que os motiva e faz reconhecer a importância de continuar a desenvolver este tipo de práticas.

A professora Aúrea refere que a abordagem experimental usada na formação, bem como as metodologias de implementação da mesma, nomeadamente a "descentralização da ação do professor do resultado para o processo", são promotoras de "tarefas propulsoras das verdadeiras caminhadas experimentais". Estas perceçōes da professora estão de acordo com vários estudos que indicam que um modelo de formação de professores que envolve o questionamento investigativo, em vez de um modelo centrado no professor, aumenta a probabilidade de estes adotarem formas de ensino mais construtivistas e centradas nos estudantes (OECD, 2014; PRIMAS, 2011). Deste ponto de vista, consideramos que este formato é promotor da eficácia do desenvolvimento profissional dos professores.

Os professores Anacleto e Micaela, inovaram as suas práticas, realizando atividades relacionadas com as STEM, que não eram habituais no seu quotidiano. Para além de criaram e implementaram diversas tarefas de matemática, a partir da atividade experimental relacionada com o som, reconheceram a importância de realizar este tipo de abordagem com os seus alunos.

Defendemos que foi o contexto formativo colaborativo com uma forte componente prática que motivou e deu confiança aos professores para realizarem atividades experimentais que não fazem parte da sua prática habitual. Tal como referem Afonso, Neves e Morais (2005), os professores devem experienciar o que se espera que venham a implementar com os respetivos alunos, num ambiente de grande apoio aos mesmos, de forma a tomarem como suas as práticas desenvolvidas. Este aspeto está de acordo com outros autores tais como Zehetmeier, Andreitz, Erlacher e Rauch (2015) que referem que as inovaçōes devem 
ser apropriadas pelos professores que as implementam e transformadas na sua própria prática de modo a terem efeitos significativos. Consideramos que foi o que aconteceu com os professores Anacleto e Micaela que passaram por um processo de formação com STEM e desenvolveram as suas próprias práticas.

No 1. ciclo de TDR praticamente não foram propostas tarefas interdisciplinares relacionadas com o som. Já no 2. ciclo, os professores Anacleto e Micaela são exemplos de como podem ser desenvolvidas tarefas interdisciplinares relacionadas com o som. Consideramos que foi o contexto formativo onde foi reforçada a componente prática e o apoio aos professores que levou os professores a inovarem as suas práticas.

Conclui-se que é possível trabalhar a matemática, a partir do som, através de um contexto de desenvolvimento profissional colaborativo, que exemplifica esta abordagem e onde os professores são apoiados na implementação das suas práticas.

\section{REFERÊNCIAS BIBLIOGRÁFICAS}

Abell, S. K., \& McDonald, J. T. (2006). Envisioning a curriculum of inquiry in the elementary school. In L. B. Flick \& N. G. Lederman (Eds.), Scientific inquiry and nature of science: Implications for teaching, learning, and teacher education (pp. 249-261). Dordrecht, Boston: Springer.

Afonso, M., Neves, I., \& Morais, A. M. (2005). Processos de formaçāo e sua relaçāo com o desenvolvimento profissional dos professores. Revista de Educaçāo, 13(1), 5-37.

Ball, D. L. (2003). Mathematics in the $21^{\text {st }}$ century: What mathematical knowledge is needed for teaching mathematics. Paper presented at the Secretary's Summit on Mathematics, U.S. Department of Education, Washington, DC.

Bannan-Ritland, B. (2000). Teacher Design Research. An emerging paradigm for teachers' professional development. In A. E. Kelly \& R. A. Lesh (Eds.), Handbook of Research Design in Mathematics and Science Education, pp. 246-262. Mahwah, NJ: Lawrence Erlbaum.

Beane, J. A. (1995). Curriculum integration and the disciplines of knowledge. The Phi Delta Kappan, 76(8), 616-622.

Berlin, D. F., \& Lee, H. (2005). Integrating science and mathematics education: Historical analysis. School Science and Mathematics, 105(1), 15-24.

Baxter, J. A., Ruzicka, A., Beghetto, R. A., \& Livelybrooks, D. (2014). Professional development strategically connecting mathematics and science: The impact on teachers' confidence and practice. School Science and Mathematics, 114(3), 102-113. 
Cohen, L., Lawrence, M., \& Keith, M. (2007). Research Methods in Education. 6th Edition. Taylor and Francis Group

Costa, M. C.; \& Domingos, A. (2018). Promoting STEAMH at primary school: a collaborative interdisciplinary project. New Trends and Issues Proceedings on Humanities and Social Sciences. 4(8), 234-245.

Costa, M. C.; \& Domingos, A. (2017). Innovating teachers' practices: potentiate the teaching of mathematics through experimental activities. In CERME 10. Dublin. In Proceedings of CERME 10.

Diário da República (2017). Despacho n. 5908/2017, de 5 de julho. Acedido através de http://www.dge.mec.pt/sites/default/files/Curriculo/Projeto_Autonomia_e_Flexibilidade/despacho_5908_2017.pdf.

Ferreira, C., Neves, P., Costa, C., \& Teramo, D. (2017, June). Socio-constructivist teaching powered by ICT in the STEM areas for primary school. In Information Systems and Technologies (CISTI), 2017 12th Iberian Conference on (pp. 1-5). IEEE.

Geiger, V., Goos, M., Dole, S., Forgasz, H., \& Bennison, A. (2014). Devising principles of design for numeracy tasks. In Curriculum in focus: Research-guided practice: Proceedings of the $37^{\text {th }}$ annual conference of the Mathematics Education Research Group of Australasia,. pp. 239 - 246.

Gillies, R. M., \& Nichols, K. (2015). How to support primary teachers' implementation of inquiry: Teachers reflections on teaching cooperative inquiry-based science. Research in Science Education, 45(2), 171-191.

Hewson, P.W. (2007). Teacher Professional Development in Science. In Abell, S. K., \& Lederman, N. G., Handbook of research on science education. New York: Routledge.

Kermani, H., \& Aldemir, J. (2015). Preparing children for success: Integrating science, math, and technology in early childhood classroom. Early Child Development and Care, 185(9), 1504-1527.

Kim, D., \& Bolger, M. (2017). Analysis of Korean elementary pre-service teachers' changing attitudes about integrated STEAM pedagogy through developing lesson plans. International Journal of Science and Mathematics Education, 15(4), 587-605.

Ministério da Educaçāo (2013) Metas Curriculares de Matemática. Programa de Matemática para o ensino básico - 1. Ciclo. Lisboa: Departamento da Educaçāo Básica. Retrieved from http://www.dge.mec.pt/matematica.

Ministério da Educação (2007) Programa de Estudo do Meio para o ensino básico - 1.ำ Ciclo. Lisboa: Departamento da Educaçāo Básica. Ministério da Educaçāo. Retrieved from http://www.dge.mec.pt/ estudo-do-meio. 
Mody, C. C. M. (2015). Scientific practice and science education. Science Education, 99(6), 1026-1032.

Murphy, C., Smith, G., Varley, J., \& Razı, Ö. (2015). Changing practice: An evaluation of the impact of a nature of science inquiry-based professional development programme on primary teachers. Cogent Education, 2(1), 1077692.

OECD. (2014). Education at a glance 2014: OECD indicators. OECD Publishing. doi:10.1787/ eag-2014-en. Accessed September 18, 2017.

Osborne, J., \& Dillon, J. (2008). Science education in Europe: critical reflections. London: The Nuffield Foundation.

PRIMAS (2011). The PRIMAS project: Promoting Inquiry-based Learning (IBL) in mathematics and science education across Europe. European Union: Capacities. http:// www.primas-project.eu Consultado 20/01/2017.

Rocard, M., Csermely, P., Jorde, D., Lenzen, D., Walberg-Henriksson, H., \& Hemmo, V. (2007). Science education now: A renewed pedagogy for the future of Europe. Bruxelas: Comissão Europeia.

Treacy, P., \& O'Donoghue, J. (2014). Authentic Integration: a model for integrating mathematics and science in the classroom. International Journal of Mathematical Education in Science and Technology, 45(5), 703-718.

Yin, R. K. (2005). Estudo de caso: Planejamento e métodos (3. Ed). Porto Alegre: Bookman.

Zehetmeier, S., Andreitz, I., Erlacher, W., \& Rauch, F. (2015). Researching the impact of teacher professional development programmes based on action research, constructivism, and systems theory. Educational action research, 23(2), 162-177.

\author{
MARIA CRISTINA OLIVEIRA DA COSTA \\ Dirección: Unidade Departamental de Matemática e Física, Escola Superior de Tecnologia \\ Instituto Politécnico de Tomar, Estrada da Serra, 2300-313 Tomar, Portugal \\ Teléfono: $\quad+351249328100$ \\ URL: $\quad$ http://www.ipt.pt/
}

